\title{
Observaciones Sobre Algunas Obras de la Avellaneda Publicadas en México
}

\begin{abstract}
A LGUNAS obras de Gertrudis Gómez de Avellaneda -draA mas, novelas, cuentos, poesías $y$ apuntes autobiográficos-, aparecieron en México en ediciones muy curiosas e interesantes, Como resultado de su estudio, podemos presentar una lista de datos nuevos y curiosos. ,

Era de esperarse el hallar, en las preciosas colecciones de los bibliófilos, una cantidad representativa de estas ediciones mexicanas. En algunos casos obras de la Avellaneda están encuadernadas con las de otros autores, por ejemplo, ciertos dramas y novelas - lo que resulta notable si se comparan las producciones de aquélla con las de éstos.

Se arregla aquí primero una bibliografía de obras en general, en orden cronológico; sigue después una lista de poesías sueltas; $y$ al fin se dan algunas observaciones hechas por críticos de México.
\end{abstract}

\section{PRIMERA PARTE}

\section{Bibliografía}

1). 1851 DOÑA GERTRUDIS GOMEZ AVELLANEDA DE SABATER (sic). Apuntes biográficos. En | LA ILUSTRACION | MEXICANA | Publicada | por | I. Cumplido. | 1881. | [25 cms.] Véanse pp. 424-428. (Acompaña el artículo un retrato muy lindo en litografía, diferente del que se publicó en 1850 en La Ilustración... de Madrid, p. 351). (2). 
2). 1851 LA MONTAÑA MALDITA. Tradición suiza. Ibid., pp. 381-387. (3):

3). 1851 DOLORES. | (Adorno tipográfico) | Novela historica (sic) | escrita por la Señorita | Doña Gertrudis Gómez (sic) de Avellaneda. | (Adorno tipográfico) | Mexico (sic). I Tipografia (sic) de Vicente G. Torres. $1851 . \mid 169$ pp. [19 cms.] (4).

4). 1852 POESIAS | de | la Excma. Sra. | Doña Gertrudis Gomez (sic) de Avellaneda | de Sabater. | Méjico. | Imprenta de Juan R.

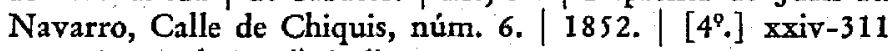
pp. más tres hojas de índice y un retrato. (5).

5). 1853 CUATIMOZIN, | ULTIMO | EMPERADOR DE MÉJICO. | Novela histórica | por la Señorita Gomez de Avellaneda. | (Adorno tipográfico) | Méjico. | Imprenta de Juan R. Navarro, calle de Chiquis número $6 .|1853| 178,.[2] \mathrm{pp}$. [27 cms.] (6).

Reimpresión en 1887:

GUATIMOZIN, | ULTIMO | EMPERADOR DE MEXICO. | (Adorno tipográfico) | Novela historica (sic) / por la Srita. (sic) Gomez de Avellaneda. | Edición del "Diario del Hogar." (sic) | (Adorno tipográfico) | México. $|-|$ Tipografia literaria de Filomeno Mata | San Andrés y Betlemitas 8,9 y esquina. $|-| 1887 \mid[15 \mathrm{cms}$. $]$ (7).

Traducción al inglés en 1898:

CUAUHTEMOC, | THE LAST AZTEC EMPEROR. | An Historical Novel | by | Doña Gettrudis Gomez de Avellaneda. | - | Translated by | Mrs. Wilson W. Blake | (Adorno tipográfico) | Mexico |-| F. P. Hoeck, Publisher | - | 1898 |, 1 p. 1., ii, 389 pp., frontispicio (retrato), [20 cms.] (8).

6). 1853 ARTfCULO AUTOBIOGRÁFICO, publicado en el Diccio. nario Universal de Historia y de Geografía, t. I, México. 1853, Tipografia (sic) de Rafael... Libreria de Andrade... Véanse pp. 279-280. (9).

7). 1853 ERRORES DEL CORAZÓN. Drama eñ tres actos y en prosa, Méjico, [Imprenta ?], 1853. 59 pp. [16 cms.] (10).

8). 1855 LA CAJA DE ORO | por Madama de Gomez. | (Se duda

(?) que ésta sea obra de la Avellaneda). Hacen falta el lugar y la fecha de la publicación. $56 \mathrm{pp}$. [17 cms.]. (11).

9). 1856 ESPATOLINO. | Novela original | por la Señorita | Doña Gertrudis G. (sic) de Avellaneda. | La funesta celebridad del per- | sonaje cuyo nombre ponemos por | título á (sic) esta novela, nos dispensa / de asegurar que no es un ente / imaginario, y que muchos de los | hechos que vamos á referir son | exactamente verídicos. | Mexico: 1856. | Imprenta de José 
A. Godoy, | Calle del Seminario núm. 6. 354 pp. [19 cms.] (12).

10). 1858 EL | DONATIVO DEL DIABLO. | Novela por | Doña Gertrudis G. de Avellaneda. | (Adorno tipográfico) | Méjico | Imprenta de Juan R. Navarro / Calle de Medinas núm. $24|1858|, 126$ pp. [19 cms.] (13).

11). 1887 GUATIMOZIN, |... (Véase párrafo 5 , este artículo).

12). 1898 CUAUHTEMOC, $\mid \ldots$ (Véase párrafo 5 , este artículo).

\section{SEGUNDA PARTE}

\section{Poesías Sueltas}

13). 1842 AMOR Y ORGULLO. En | PANORAMA | DE LAS SEÑORITAS. | (Adorno tipográfico) | Periodico pintoresco, cientifico (sic) y literario. ( Adorno tipográfico) Contiene varias viñetas, algunas laminas (sic) sobre acero, estampas y musica (sic) litografiada. (Adorno tipográfico: una lira) | México Imprenta de Vicente Garcia Torres, / Calle del Espíritu Santo número 2. | 1842. | Véanse pp. 307-312. (14).

14). 1842 CONTEMPLACION. Ibid., pp. 251-254. (15).

15). 1842 A LA LUNA. En | SEMANARIO | DE LAS | SEÑORITAS MEJICANAS | Educacion (sic) científica, moral y literaria, | del bello sexo. | Tomo III. | Mejico: 1842. | Imprenta de Vicente G. Torres. | Calle del Espíritu Santo $N^{q}$ 2. I, p. 345 . (16).

16). 1848 LA CLEMENCIA. Oda. En | VARIEDADES. | [1848?]

(?) (La portada y el índice están escritos a mano según el ejemplar de que nos hemos servido en la colección de Genaro García). Véanse pp. [406]-407. (17).

17). 1848 AL ESCORIAL. Ibid., pp. [495]-496. (18).

18). 1851 A LA MUERTE DEL DISTINGUIDO POETA DON JOSÉ DE ESPRONCEDA. En La Ilustración Mexicana, publicada por I. Cumplido, t. II, 1851, pp. 116-118. (19).

19). 1856 AL NACIMIENTO DEL REDENTOR. Cantico (sic). En | LA CRUŹ | - Periódico esclusivamente (sic) religioso | establecido ex profeso | para difundir las doctrinas ortodoxas, y vindicarlas $\mid$ de los errores dominantes. | Tomo IV. | (Adorno tipográfico: una cruz) | México / Imprenta de J. M. Andrade y F. Escalante / Calle de Cadena numero (sic) 13. $|-| 1856 \mid$ [25 cms.] Véanse pp. [432]-433. (20).

20). 1857 EN LOS FUNERALES DEL POETA ESPAÑOL QUINTANA. Ibid., t. V, México, 1857, p. [24] (21).

21). 1887 A CUBA. En | ACOPIO | DE SONETOS CASTELLANOS | con notas de un aficionado | que publica | D. José 
Maria (sic) Roa Bárçena: | (Adorno tipográfico) |-| (Edicion (sic) de 60 ejemplares) $|-|$ México $|-|$ Imprenta de Ignacio Escalante | Bajos de San Agustin (sic), N. $1|-|$ 1887 [ $24 \mathrm{cms}$.] Véanse pp. 111-114.

A WASHINGTON. Ibid., pp. 111-112.

LAS DOS LUCES. Ibid., p. 112.

IMITANDO UNA ODA DE SAFO. Ibid., pp. 112-113.

A DIOS. Ibid... p. 113.

AL NOMBRE DE JESUS (sic). Ibid., pp. 113-114.

\section{TERCERA PARTE}

Algunos estudios sobre la Avellaneda bechos en'Méjico

22). 1868 Altamirano, Ignacio M. ENSAYO CRÍTICO / SOBRE | BALTASAR | drama oriental | de la Señora | Doña Gertrudis Gomez (sic) de Avellaneda | Representado por la primera vez en el Gran Teatro Nacional de México | en el beneficio de la distinguida actriz / Doña Salvadora Cairon (sic) I La noche del 27 de junio de 1868. | (Adorno tipo-. gráfico) Edicion (sic) de 100 ejemplares para los amigos. 1. México Imprenta de F. Diaz (sic) de Leon (sic) y Santiago White, |Bajos de San Agustin Num. 1. $|-| 1868 \mid$ 40 pp. $[211 / 2$ cms.] (22).

23). 1887, Roa Bárcena, José María. Op. cit., [este artículo, párrafo 21] "Gertrudis Gómez de Avellaneda", pp. 114-115. (23).

24). 1895 Olavarría y Ferrari, Enrique de. RESENA HISTÓRICA | del | TEATRO EN MÉXICO | por Enrique de Olavarría y Ferrari | Segunda edicion | Tomo III | Mexico | Imprenta, encuadernacion y papeleria | "La Europea" | Propietario, Fernando Camacho. Director, Juan Aguilar Vera. | Calle de Santa Isabel núm. 9. | 1895| Vẻase p. 271, t. II; pp. 39-41 , t. III. (24).

25). 1899 Altamirano, Ignacio M. OBRAS DE D. IGNACIO M. ALTAMIRANO, t. I, Rimas, artículos literarios, México, Imprenta de V. Agüeros, 1899. (En BIBLIOTECA DE AUTORES MEXICANOS, vol. 21, pp. 161-195).

26). 1929 Romero de Terreros, Manuel. NOCIONES DE LITERATURA CASTELLANA, notas reunidas por Manuel Romero de Terreros de la Real Academia Española, Publicaciones de la Secretaría de Educación, México, D. F, 1926. (Véanse pp. $78,79,82$ ).

EDITH L. KeLLY, Los Angeles, Calif. 
(i) - Para presentar los detalles de mayor interés contenidos en las portadas de las varias ediciones de las obras de la Avellaneda fué necesario respetar en este artículo mismo la ortografía, puntuación, y hasta los errores de los redactores de otros tiempos.

Debe considerarse tentativa nuestra lista bibliográfica. Se basa en "La bibliografía de la Avellaneda" estudio hecho bajo la dirección del Profesor Alfred Coester), en la Revista Bimestre Cubana, xxxv-1, enero, febrero, 1935, pp. 107-139; 2, marzo-abril, pp. 261-296. (Una tercera parte está en prensa).

(2).-La portada de este periódico es muy pintoresca y ornada con diseños de forma clásica. Dice al margen: "C. Castro, dibujó. Litog. de Decaen".

La autobiografía es sin duda copia de la de 1850 , con ciertos cambios ortográficos, etc. Hay otras discrepancias, no obstante. Se lee, por ejemplo, en la edición de Madrid: "En 1842 aumenté mi colección poética..." (p. 345 sic), pero en la mejicana: "En 1841 aumenté mi colección poética..." (p. 427).

(3).-Esta obra apareció primero en el Semanario Pintoresco Espa$\tilde{n} o l$, Madrid, 1851, pp. 179-181. Fué reimpresa en el Album Cubano, 1860 , y pasó a figurar en las Obras literarias, t. V, Madrid, 1871, pp. $77-88$.

(4) - La novela está encuadernada con otras cuatro obras, a saber: VINETTI, | ó | LA FLOR AZUL. | (Adorno tipográfico) | Novela històrica (sic) | (Adorno tipográfico) | Mexico. | Imprenta de Vicente Garcia Torres, I á cargo de Luis Vidaurri. $1850 . \mid 55$ pp.

- LA PESCA | CON | REDES. | (Adorno tipográfico) | Novela histórica | por Alejandro Dumas. | Esta edicion (sic) es propiedad del Monitor Republicano.) | (Adorno tipográfico) I Mexico | Imprenta de Vicente Garcia Torres, | á cargo de Luis Vidaurri. | 1850 . $68 \mathrm{pp}$.

LA VENGANZA | DE LOS DIFUNTOS. | Novela fantastica (sic). ( Esta edición es propiedad del Monitor Republicano.) | (Adorno tipográfico) | Mexico | Imprenta de Vicente Garcia Torres, | á cargo de Luis Vidaurri. | 1850. | 96 pp. EL LICENCIADO | D. TADEO CRISTOBAL. | (Adorno tipográfico) | Novela mexicana. | (Adorno tipográfico) | Mexico. Imprenta de Vicente G. Torres, ex-convento del Espiritu Santo. | 1850. 38 pp.

Esta edición de Dolores es muy rara y al parecer desconocida en las listas de los bibliógrafos. En la cubierta del tomo se halla el título: Novelas. La carta que sirve de introducción debe compararse con la que se escribió al Sr. Director del Semanario Pintoresco Español, Madrid, 5 de enero de 1851, que empieza así: "Dos noches de desvelo..." La que se publicó en las Obras literarias, t. IV, es muy diferente. Se dirigió al Sr. 
Director del Diario de la Marina y empieza así: "Muy señor mío y amigo: Tres meses hace que deseo...."

El tomo a que se refiere arriba lleva el número 3959 en la Colección de Bancroft, de la Universidad de California, Berkeley. Pertenecia a la célebre biblioteca de Andrade-Maximiliano. La historia de las vicisitudes que experimentó la preciosa colección del bibliófilo J. M. Andrade, es sin duda bien conocida: cómo se entregó en su totalidad a $\mathrm{Ma}-$ ximiliano, para que fuese instalada en la Biblioteca Imperial de Méjico; cómo la rescató el bibliófilo después de la muerte del Emperador; cómo fué llevada a Veracruz por arrieros, y embarcada para Europa; cómo se dividió y se vendió en Europa, particularmente en Londres y en Leipzig. (Véase The Works of Hubert Howe Bancroft... vol. XXXIX, San Francisco, 1890, pp. 185-191).

(5).-Es la descripción que dió Cotarelo y Mori en La Avellaneda $y$ sus obras. . . Madrid, 1930, pp. 393 ff. La primera edición (POESİAS | DE | LA SEÑORITA | $D^{9}$ (sic) GERTRUDIS GOMEZ | DE AVELLANEDA. | (Adorno tipográfico: una lira) | Madrid, 1841. | (Adorno tipográfico) Establecimiento tipografico (sic), / Calle del Sordo núm. 11. 2 pp. 1., xiii, [7]-213, [s] pp. [15 cms.] con prefacio de Juan Nicasio Gallego) fué seguida de una segunda más grande:

POESIAS | DE | LA EXCELENTISIMA SEÑORA | D.A GERTRUDIS GOMEZ DE AVELLANEDA | DE SABATER. | (Adorno tipográfico) | Madrid. | (Adorno tipográfico) | Imprenta de Delgrás Hermanos, Pretil de los Consejos. | 1850. | 3 pp., 1., xx [4], 512.pp. [22 cms.], con prólogo de Júan Nicasio Gallego y un frontispicio: retrato en litografía hecho por C. Legrand y que lleva el autógrafo: | G. G. de Avellaneda |

(6).-La autora del presente artículo vió unos ejemplares de la edición mejicana en la Colección de Bancroft de la Universidad de California, Berkeley, y en la Biblioteca de la Ciudad de Los Angeles, en California. Dice en la portada:

BIBLIOTECA ILUSTRADA DE GASPAR Y ROIG. | (Adorno tipográfico) |ORLANDO FURIOSO | por Ariosto. | (Adorno tipográfico)" Adornada con 45 grabados. I (Adorno tipográfico: un retrato) | Ariosto. | Madrid | Gaspar y Roig, Editores | calle del Príncipe, núm. 4. |. (Adorno tipográfico) | $1851202 \mathrm{pp}$. más 2 hojas de índice, [25 1/2 cms.]

El libro se compró en 1926 a Porrúa Hermanos, Avenidas República Argentina y Justo Sierra, Méjico, D. F., según Mr. A. C. Read de la Biblioteca de la Ciudad de Los Angeles.

(7).-La primera edición de Guatimozín se publicó en Madrid, 18.46, 4 vols. en 2 tt., a saber:

GUATIMOZIN | ULTIMO EMPERADOR DE MÉJICO. Novela histórica | por la Señorita Gomez de Avellaneda. (Adorno tipográfico) | Tomo 1. | (Adorno tipográfico) | Ma- 
drid: Imprenta de D. A. Espinosa y Compañia, / Calle del Caballero de Gracia. | (Adorno tipográfico) | 1846. | Vol. I, 170 pp., vol. II, 148 pp., vol. III, 147 pp., vol. IV, 147 pp. [14 cms.]

(8).-Se considera ser la primera novela publicada en inglés en Méjico, según el | TENTH CATALOGUE | ... W. W. Blake, $|\ldots|$ Mexico | (sic) Tip. "El Faro". 5? Héroes, $83 \mid 1910$ | Véase el número $5852)$.

(9).-Al parecer, esta autobiografía es una reimpresión de la que se halla en el Diccionario Universal de bistoria y de geografía. . . t. I, Madrid. .. D. Francisco de Paula Mellado, Editor... 1846. Una comparación entre esta versión y la del Diccionario universal, que se publicó en Méjico, indica que hay diferencias en la ortografía y en la puntuación, siendo la forma de ésta bastante arcaica.

(10). - Es una edición rara en forma de folleto. Véase el catálogo de W. W. Blake, (op. cit.), número 5854 . El drama se publicó primero en Madrid, 1852, Imp. de don José María Repullés, 60 pp.

(11).-La cubierta de este libro tiene el título: La caridad. Hay en el tomo otras cuatro novelas:

LOS SALVAJES | Ó LA CARIDAD. | Historia americana | traducida expresamente para "La Verdad". | Por | Elias Romero. | (Adorno tipográfico) | Mejico. | Imprenta de Tomás S. Gardida, calle de San Juan | de Letran (sic) núm. 3. | 1855. | $103 \mathrm{pp}$.

CHALMA Y SU SANTUARIO. | por ] J. M. D. | pp. [105]144.

EL | SUEÑO DE LA MARQUESA. | Novela escrita en francés por Octavio Feré, | y traducida al español por N. A. I pp. [59]-117.

EL | BUSCADOR DE ORO | EN CALIFORNIA. | Novela traducida del francés para LA VERDAD | por | Niceto de Zamacois. | (Adorno tipográfico) | Méjico.. Imprenta de Tomás S. Gardida, calle de S. (sic) Juan de Letran núm. 3. 1 1855. 81 pp. más indice.

La señora Edna Martin Parratt, una de las bibliotecarias de la Colección de Bancroft de la Universidad de California, Berkeley, nos mostró esta obra. El tomo tiene cuatro ex libris muy interesantes, a saber: el de J. M. Andrade, Maximiliano, el señor Bancroft y la Universidad de California. Puesto que Paul Henri Féval y Madeleine Angèlique Poisson se han servido del seudónimo Madama de Gomez, hay aquí un problema que debe investigarse y solucionarse si fuere posible, antes de saberse si la Avellaneda es la Madama de Gomez autor de La caja de oro.

(12).-Es la descripción del ejemplar que pertenece a THE HISPANIC SOCIETY OF AMERICA, Nueva York. Cotarelo habrá visto la misma edición. Se publicó primero en Madrid, 1844, en El Laberinto. 
(13).- ¡He aquí una edición rara! El ejemplar que nosotros vimos. está encuadernado con otras novelitas de varios autores. En la cubierta del tomo se halla el título: Varias novelas. El orden de las páginas es muy irregular. El libro pertenecía a la famosa colección de AndradeMaximiliano, y se halla ahora en la Colección de Bancroft, de la Universidad de California, Berkeley. El título en la anteportada es: BIBLIOTECA | DEL ECO NACIONAL. | El donativo del diablo se publicó primero en forma de drama en tres actos y en prosa, Madrid, Imp. a cargo de C. González, calle del Rubio, núm. 14, 1852. 69 pp. (El drama se representó por primera vez en Madrid, en el Teatro del Príncipe, el 4 de octubre de 1852). Una tradición suiza sirvió de base para la leyenda: La velada del belecbo o el donativo del diablo, otra obra de la Avellaneda que se publicó en el Semanario Pintoresco de Madrid, 1849, pp. 170-220. Se reimprimió en Nueva York en 1859 en la colección de novelas de La Crónica. Entró a figurar en las Obras literarias, t. $\mathrm{V}, \mathrm{Ma}$ drid, 1871, de la autora).

Las novelitas encuadernadas con la novela $-E l$ donativo del diablo, Méjico, 1858-son:

LA | DUQUESA DE BORGOÑÁ. | Novela escrita en frances (sic) | por | M. de Saint-Félix. | [Felix d'Amoreux] Méjico | Imprenta de Juan $\mathrm{R}$. Navarro Calle de Medinas núm. 24 | 1858 | $213 \mathrm{pp}$.

TAN JOVEN Y MORIR. | Por Federivo (sic) de Sezanne. | pp. [215]-365.

EL CENTINELA PERDIDO, | Por Federico de Sezanne. | pp. [267]-284.

LA FANTASMA. | AVENTURA VERDADERA, | Acaecida en Sicilia en el año de 1808. I pp. [127]-139.

EL PINTOR | DE WEIMAR. | pp. [141]-151.

EL ESPEJO Pp. [153]-158.

DIANA. | Novela escrita / por | D. José M. Roa Bátcena. | (Adorno tipográfico) | Mejico (sic) I Imprenta de Juan R. Navarro | Calle de Medinas nim. 24|1857| 154 pp. (La obra está dedicada al hermano del autor $D$. Rafael).

(14).-En la p. 311, en la primera estrofa se halla este verso: "Ese nombre hechicero" que la Avellaneda cambió más tarde por "Ese nombre que quiero". Véase Obras literarias, t. I, Madrid, 1869, p. 107. Esta poesía se publicó primero en Poesías de la señorita da. Gertradis Gomez de Avellaneda, Madrid, 1841 (véase nota (5), este artículo).

Gracias a la señorita $M$. Wilson, de la Biblioteca de la Universidad de Tejas, nosotros pudimos examinar este interesante ejemplar del Panorama, que pertenecía al renombrado bibliófilo Genaro García y antes a J. M. Andrade, según los ex libris.

(15).-La que aqui se halla es la forma primitiva del poema. La Avellaneda lo cambió después desde el primero hasta el último verso. En su forma definitiva se publicó en las Obras literarias, t. I, p. 98. 
(16).-Este poema fué modificado y ampliado más tarde. Véase Obras literarias, t. I, p. 102.

(17).-Así era el poema antes de figurar en la colección de Poesías, Madrid, 1850 (véase nota (5), este artículo). La Avellaneda cambió el título de esta composición por el de "Gloria de los reyes", y viceversa. Los dos premiados poemas pasaron a figurar en las Obras literarias, t. I, pp. 182 y 176 respectivamente.

Debido a los esfuerzos de la señora Verona G. Phillips, de la Biblioteca de la Universidad de Tejas, fué posible verificar algunos datos concernientes a Variedades y otros periódicos. Esta revista es al parecer muy rara. Se halla otro ejemplar [1848?], sin portada alguna, en Londres; The British Museum.

(18).- He aquí una versión diferente de la que entró a figurar en las Obras literarias, t. I, p. 186. (El poema termina con la firma de la autora y esta nota: (GERTRUDIS GOMEZ DE AVELLANEDA. | San Lorenzo del Escorial á 28 de junio de 1845. |).

(19).-Es al parecer una versión única (compárese con la de Obras literarias, t. I, p. 124), como lo indica la nota de los redactores que dice: Insertamos esta sentida composicion (sic) de la célebre | po t sa (sic), porque no se encuentra en las ediciones $\mid$ de sus obr $s$ (sic) que circulan en México, seguros ademas (sic) de / que el público la verá con aprecio.-RR. I

(20).-Así está firmado el poema: | G. G. DE AVELLANEDA. | En Obras literarias, t. I, p. 368, el título es: "Al nacimiento del Mesías. Himno". El texto es muy diferente también; por eso hemos de concluir que la forma que se halla en la revista $L a$ Cruz es bastante primitiva, pucsto que el poema no entró en las colecciones de la poetisa hasta 1869. Hay una nota de los redactores: | En los periódicos españoles recientemente llegados, hallamos la siguiente | composicion, que es una de las últimas de la célebre poetisa cubana D.a Gertrudis | Gomez de Avellaneda.-RR. " $L_{a}$ Cruz". |

(21).-Aquí tenemos otro poema que sufrió algunos cambios antes de publicarse en 1869 en las Obras literarias, t. I, p. 304, con el título: "En la muerte del laureado poeta Señor Don Manuel José Quintana". Hace falta en la versión mexicana esta observación de la autora: | Estos versos fueron improvisados y recitados por la autora en el | cementerio donde se daba sepultura al gran poeta, con cuya amistad se | honraba. | El poema en La Craz lleva la firma de la autora: | GERTRUDIS GOMEZ DE AVELLANEDA.

(22).- Se halla un ejemplar de esta obra en la Biblioteca de la Universidad de Tejas, en la Colección de Genaro García. En la portada del libro hay una nota escrita a mano que dice: Al ilustrado jurisconsulto $D$. Justo Benites. | Su apasionado amigo. | Ignacio M(sic) Altamirano. |

Véase Revista de Cuba, vol. VII, No 4, abril de 1880, Ignacio M. Altamirano, "Biografía y ensayo crítico sobre Baltasar", pp. 242-256, $365-380$. 
(23).-Por ser muy aficionado a la lírica de la poetisa, Roa Bárcena la elogia con entusiasmo en sus observaciones, pp. 114-115. (Hay una equivocación en el segundo párrafo, p. 114. La fecha de la colección de las Poesias a que se refiere debe ser 1841).

(24).-Lo que dice Olavarría (op. cit., t. III, p. 41) es de sumo interés: | Con motivo de la representación de Baltasar, el Maestro Altamirano escribió un "Ensayo crítico" del drama de la Avellaneda. Pu- 1 blicado primero en El Siglo, é impreso en edición de cien | ejemplares por Díaz de León, ese estudio magnífico es un modelo / inimitable de revista literaria que honra a su autor y es orgullo de las | letras mexicanas. Nada en su género le conocemos superior.

Hay ejemplares - [24 cms.] - de la obra de Olavarría y Ferrari en las dos bibliotecas de la Universidad de California, en Berkeley, y Los Angeles. 